\title{
Història (inacabada) del nostre Anuari: 25 anys ben fructífers
}

\author{
JoAn Verdegal (verdegal@uji.es) \\ Universitat Jaume I
}

La gestació de l'Anuari de l'Agrupació Borrianenca de Cultura va començar per iniciativa de Joan Ramon Monferrer, quan aquest era síndic major de l'ABC i exercia de secretària Teresa Esteve $(\dagger 2013)$. La proposta va quedar recollida per primera vegada en l'acta de l'Assemblea general ordinària del 29 de novembre de 1987, celebrada al local del carrer Major número 11. Després de reiterades al·lusions en dues reunions posteriors (en el consell de síndics del 9 de gener de 1988 i en el del 6 de desembre del mateix any), es va materialitzar en l'època de presidència de Teresa Esteve, en assumir Joan Garí -aleshores síndic en cap- el repte de la posada en marxa. Amb aquests antecedents, l'Anuari va nàixer un bon dia de l'any 1990, amb el propòsit de donar cobertura a articles sobre investigacions diverses d'interès general. El títol complet (Anuari de l'Agrupació Borrianenca de Cultura. Revista de recerca humanística i científica) donava ja en aqueix moment una idea de les perspectives: acollir treballs no solament relacionats amb aspectes culturals lligats al patrimoni, a la història, a les arts o a la filologia - per exemple-, sinó abraçar també altres àmbits del saber, tradicionalment més allunyats de les preferències que l'ABC havia tingut fins aleshores. Es tractava, al capdavall, de normalitzar la paraula cultura, $\mathrm{i}$ oferir un ventall de possibilitats als investigadors de tot el món -en cap moment es va pensar en restriccions localistes. Aqueixa aposta era certament arriscada, entre altres coses perquè implicava tàcitament un compromís de continuïtat de la publicació al llarg dels anys, $i$ això suposava invertir en temps i diners, dos condicionants que - ja sabemno sempre estan disponibles. Així doncs, el camí va començar com comencen normalment tots els projectes: amb illlusió, concreció d'idees al voltant del disseny de la futura revista, sol-licitud de permisos corresponents, pressupostos d'edició i impressió, localització i invitació a un grapat d'autors disponibles, etc. Les intencions del primer número -i dels altres - poden llegir-se en la presentació i en els preàmbuls successius, però la finalitat d'aquesta exposició va una mica més enllà, amb la intenció de recollir allò que no sempre és explícit i que confereix el tarannà a una trajectòria de vint-i-cinc anys d'una revista local amb projecció internacional.

\section{Les miscel·lànies (1990-1996)}

El número i de l'Anuari naixia l'any 1990, amb deu articles i una breu presentació del director - Joan Garí-, qui al-ludia a una «mudança plena d'esperances» a les terres de Castelló, on la futura Universitat faria necessaris nous instruments per a una nova realitat cultural, en la qual l'ABC pretenia aportar «l'eina que potser més bon paper farà en atenció a les noves necessitats: aquest Anuari». El format inicial (imprès a Gràfiques Ventura, Borriana), amb dipòsit legal i ISBN, va ser efímer. Es va modificar l'any següent per un 
altre més modern (confeccionat a la Impremta Sichet, Vila-real), amb un ISSN definitiu. El pas següent va ser negociar i preparar un conveni de col-laboració amb la Universitat Jaume I, que van signar, l'any 1992, el rector Francesc Michavila i el síndic major Joan Garí, tot just quan s'encetava el camí de l'Anuari i quan l'UJI acabava d'obrir les seues portes. El relleu de Joan Garí com a director de la revista el va agafar Tomàs Martínez, l'any 1992, qui la va dirigir en solitari durant dos números, ajudat, en el de 1994, per Joan Verdegal com a secretari, qui va passar a ser director el 1995 (i fins a l'actualitat). Aquesta etapa de consolidació es tancava amb el número de 1996, que inclö̈a un dossier inicial de tres articles titulat Discurs literari en femení, que el director justificava succintament en la presentació: «[...] amb la introducció d'aquesta particularitat, volem donar pas a una nova vocació que hem adquirit amb la maduresa que atorga l'edició, any rere any, d'una publicació com la nostra: la monografia».

\section{Els monogràfics (1997-2014)}

L'impuls i la idea d'aquesta llarga trajectòria monogràfica va nàixer de la conveniència d'adaptar-se a les noves tendències en matèria de publicacions periòdiques, que propugnaven una concentració temàtica més atractiva per als investigadors i, al mateix temps, més profitosa per als lectors. Es tractava, doncs, d'oferir als socis de l'ABC - però també a altres públics - la possibilitat de disposar de volums que pogueren servir com a complements de formació o com a manuals universitaris, però amb la particularitat d'acostar els temes amb una certa vocació divulgadora. Aquest va ser el propòsit del director de l'Anuari i aquests han estat els resultats.

El primer monogràfic pròpiament dit va veure la llum el 1997 al caliu d'una fita important: el compliment del sisè centenari del naixement d'Ausiàs March. Calia celebrarho amb aportacions sobre el Segle d'Or valencià, on la presència dels nostres clàssics de la literatura fóra coordinada pel professor Tomàs Martínez Romero. Així doncs, el títol i subtítol del volum viII (Lo gentil estil fa pus clara la sentència. De literatura $i$ cultura a la València medieval) s'encetava amb una sobrecoberta cedida per l'artista Andreu Alfaro que, amb variacions cromàtiques, havia de ser la carta de presentació cap al futur.

L'any 1998, tot just quan eixia la primera promoció de llicenciats i llicenciades en Traducció i Interpretació de l'UJI, apareixia un monogràfic amb un títol emprat a l'humanista valencià Joan Lluís Vives (Verba enim finita sunt, res infinitae. De l'activitat traductora i literària); l'objectiu era demostrar que la traducció és alguna cosa més que una activitat subsidiària, i l'encarregat de coordinar aquell número Ix era el professor Joan Verdegal.

El volum número x de l'Anuari va ser producte d'una invitació adreçada al director dels Estudis per la Pau de la Universitat Jaume I. Era el moment de recapitular sobre la implantació real dels Drets Humans, cinquanta anys després d'haver estat promulgats, quan estàvem a punt de canviar de millenni i d'acomiadar el segle més sanguinari de la història, que s'acabava amb la traumàtica experiència europea de les guerres balcàniques. El resultat era un monogràfic de gran interès i actualitat, coordinat pels professors Vicent Martínez Guzmán i Irene Comins Mingol, amb el títol i subtítol següents: Terra i drets. Els drets humans i la pau a la fi del mil·lenni. 
A proposta del professor Vicent Salvador Liern, el número XI (Saber i comunicar. Discurs científic i comunicació social) havia de recollir reflexions transversals sobre les noves revolucions en el món de la comunicació i de la ciència, i acostar-nos als condicionants poderosos d'una quotidianitat que ha aprofitat tot un ventall de possibilitats superadores del discurs científic prototípic d'èpoques passades.

L'any 2001 era propici per a seguir parlant de ciència; amb el rerefons de la novel·la futurista d'Arthur C. Clarke i del film de Stanley Kubrick, el director de l'Anuari s'adreçava al professor Josep Planelles Fuster amb un oferiment concret: un monogràfic que incloguera en el títol dues coses: 2001 i odissea. Amb el concurs del professor Federico García Moliner, premi Príncep d'Astúries d'Investigació Científica i Tècnica el 1992 i síndic d'honor de l'ABC el 1993, es publicava el número XII, amb resultats i crítiques excel·lents: 2001: l'odissea de la física. Paradigmes i aplicacions de la física contemporània.

Amb el propòsit de desvelar la importància de la crítica com a veu col-lectiva i personal en el coneixement de l'art i de la literatura, el professor Lluís Meseguer aglutinava una plantilla de joves investigadors en el volum de 2002 - el número XIII- que aportaven certament perspectives ben aclaridores i les relacionaven amb la vida quotidiana: Criticar no és ofendre. L'estat de la crítica literària entre segles.

L'any següent, el 2003, un oferiment directe del professor Amador Antón, que seguia la trajectòria de l'Anuari, va quallar amb la coordinació del monogràfic Conversa intercultural. Comportaments i relacions en el món humà. Aquest número XIV tractava d'alertar, des de perspectives diverses i concretes, sobre els perills que les tendències de convergència globalitzadora poden representar per al reconeixement de les diferències culturals i lingüístiques entre els pobles.

El 2004, la nostra societat acabava de ser protagonista de certs conflictes relacionats amb l'aprofitament dels recursos hídrics; tocava doncs aprofitar la conjuntura i donar veu als experts en aquest tema, fora d'apassionaments acientífics i d'interessos partidistes. A l'efecte, es va convidar la professora Leonor Lapeña, qui, amb la col·laboració d'Isabel Queral, experta en la primera línia de la defensa ecològica, coordinaven el número xv, imprescindible per a crear opinió assenyada sobre el tema: Preservar l'aigua, conservar la vida. Un compromís social i ambiental.

El volum següent pretenia presentar una «fotografia» de la situació de les llengües europees sense Estat, però el calat del projecte obligava a concebre dos volums diferents. En efecte, el número xvi (de 2005), coordinat pels professors María Dolores Burdeus i Joan Verdegal, aconseguia contactar amb setze experts en llengües minoritàries, amb un resultat centrat en les llengües hereves del llatí: Europa parla (I). Llengües romàniques minoritzades d'Europa. A més, s'encetava una millora del conveni entre l'Agrupació Borrianenca de Cultura i la Universitat Jaume I, en què participava el Departament de Traducció i Comunicació, el qual aportava traductors remunerats mitjançant el seu Pla Estratègic. El volum concloïa amb una simbòlica carta de comiat titulada «Em diuen Omega» i publicada en les diverses llengües romàniques, a manera de testimoni futurista de la possibilitat de desaparició d'aquestes llengües l'any 3005.

Com a continuació de l'anterior, tot fent-se ressò d'allò que havia significat l'Any Europeu de les Llengües promogut per la Unió Europea (2001), així com del repte que suposava l'ampliació dels Estats membres fins a vint-i-cinc, el número XVII de l'Anuari 
(2006) recollia vuit articles sobre sengles llengües de l'àmbit no romànic, aquesta vegada sota la coordinació compartida entre els professors Josep R. Guzman i Joan Verdegal: Europa parla (II). Llengües no romàniques minoritzades d'Europa. El volum també acabava amb les corresponents versions de la carta «Em diuen Omega». S'hi incorporava per primera vegada als monogràfics, a més de l'ISSN, un ISBN.

L'arribada de l'any 2007 significava una oportunitat per a rememorar el tercer centenari de la desfeta d'Almansa i el que això havia significat per al nostre poble; a més, en 2006 s'havia aprovat el nou Estatut d'Autonomia. L'efemèride, doncs, mereixia ser tractada com calia, i per això el director de l'Anuari es va adreçar al professor Vicent Ortells Chabrera, qui va declinar en un principi la proposta per motius de treball, però que la va acceptar després amb la condició de rebre l'ajuda del mateix director. Així va nàixer el número XVIII, que aconseguia donar una visió històrica dels canvis soferts per la societat valenciana al llarg de tres centúries, però també en el context dels últims trenta anys: L'autonomia retrobada. Perspectives i prospectives del País Valencià (1707-2007). De manera excepcional, en atenció al tema que s'hi abordava, van ser convidats a expressarse els partits polítics amb representació a les Corts Valencianes. Aquest número introduïa també un consell de redacció, format pels coordinadors de tots els monogràfics, que es rellevarien amb el pas dels anys.

L'any següent, quan ja s'albiraven els inicis d'una crisi econòmica que havia d'afectar especialment el context immobiliari, per mediació del professor Josep Planelles es va contactar amb especialistes del món de la ceràmica, activitat important i capdavantera de la província de Castelló. El resultat va ser un Anuari de 2008 amb tres parts ben delimitades, recollides en el subtítol i coordinades respectivament pels professors Elvira Gual, Vicent Cantavella i Guillermo Monrós: La nostra ceràmica. Art, indústria i recerca en la ceràmica valenciana. El número XIX, doncs, oferia una visió actual de l'activitat amb més projecció internacional de la nostra economia.

Per a 2009 es va buscar també un tema amb repercussions directes sobre l'economia: el turisme. Com a especialista de la gestió turística, es va oferir el número xx al professor Diego López, qui va aprofitar la seua experiència per a coordinar un volum ben útil per a la dinamització i consolidació d'un sector turístic que ha de comptar irremissiblement amb el medi natural on es troba incardinat: Turisme i territori. La sostenibilitat com a referència.

Amb una trajectòria consolidada de vint números consecutius i una presència visible a la Universitat Jaume I -d'on procedeixen els coordinadors-, l'Anuari rebia, en 2010, un oferiment que el desviava en certa manera dels números anteriors. Es tractava d'una proposta que, consultada primerament amb el professor Tomàs Martínez, desembocava en una oferta completament femenina: Marina López Martínez plantejava l'edició d'un volum que abordara el fenomen de la identitat nacional des de la perspectiva de les dones i dels nacionalismes. Nou mesos després naixia el número xxı: Pensar la nació en femení. Una construcció inacabada.

Mentrestant, fruit d'una invitació procedent del Consorci de Biblioteques Universitàries de Catalunya, que s'interessava pels continguts de la revista i que en reconeixia la trajectòria de difusió humanística i científica, amb data 1 de setembre de 2010, es va signar un conveni entre l'UJI, el CBUC i l'ABC, el que significava poder consultar en Internet tots els articles publicats a l'Anuari des de l'any 1990, mitjançant el RACO (Revistes Catalanes amb Accés 
Obert). D'altra banda, per iniciativa del director, es produïa una doble renovació en la revista, que va consistir a ampliar els consells (de redacció i assessor) i en l'adaptació del format als criteris Latindex (per a fer-la més atractiva als col-laboradors i poder indexar-la en diverses bases de dades).

Amb la perspectiva de la inauguració dels estudis de Ciències de la Salut a la Universitat Jaume I, i tenint en compte que els departaments de Psicologia adscrits fins al moment a la Facultat de Ciències Humanes i Socials es disposaven a canviar de Facultat, es va considerar l'oportunitat de preparar un monogràfic per a 2011 que posara en relleu el paper d'aquesta ciència en la qualitat de vida de les persones. L'encarregat de coordinar aquest número XXII era el professor Jesús Rosel Remírez, amb el següent desenllaç: Psicologia positiva. Millora de la qualitat de vida per mitjà de la psicologia.

Així doncs, l'any 2012, després de quatre anys de forta crisi econòmica - que havia obligat l'Anuari a limitar el nombre de pàgines-, calia preguntar-se com s'havia pogut caure en aquesta situació i si la societat globalitzada sabria aprofitar-ne la lliçó. L'encàrrec es va adreçar aleshores al professor Germán Orón, qui va preparar un volum de gran actualitat amb el títol de Crisi i internacionalització econòmica. Perspectiva jurídica i econòmica de la crisi global. Aquest número abandonava la sobrecoberta que havia funcionat des de l'any 1997, però conservava el disseny d'Andreu Alfaro (mort precisament aqueix any) i afegia el sumari a la contracoberta. La nova presentació, amb tractament protector i estampació a una tinta i pel-liculat mat, resultava més moderna i li conferia definitivament la categoria de llibre. Es renovaven el consell de redacció i el consell assessor, amb la finalitat de complir amb els criteris de qualitat de les agències avaluadores de revistes. També s'hi incorporaven les indexacions en bases de dades i els enllaços d'accés a les versions digitals per Internet.

El 2013 calia retornar a les arts, i s'escollia un tema amb gran tradició valenciana: la música. L'encàrrec, acceptat de bon grat pel professor Antoni F. Ripollés, es materialitzava en un volum que reivindicava principalment el nom i les aportacions de músics castellonencs del segle xx; el títol escollit era La nostra música. Autors, gèneres, estils i recerca de les comarques de Castelló. S'hi afegien bionotes sobre els autors després de cada bibliografia, així com — a peu de cada pàgina - el DOI (Digital Object Identifier) per a cada article.

Finalment, amb motiu del vint-i-cinquè aniversari de l'Anuari, es preparava per a l'any 2014 un monogràfic amb una inevitable protagonista: Borriana. L'efemèride requeria donar cobertura als problemes i a la realitat de la nostra ciutat, com a prototip de localitat valenciana acostada a la mar. A l'efecte, amb la col·laboració de tots els membres del consell de redacció i del consell assessor de la revista, naixia la proposta per al monogràfic Evolució de la ciutat mitjana valenciana cap al segle XXI. El cas de Borriana, coordinat pels professors Joan R. Monferrer i Antoni Gil, amb aportacions procedents d'investigadors borrianencs. En la pàgina de crèdits s'afegia un ISSN electrònic.

En definitiva, la història fructífera del nostre Anuari - que encara és inacabada - ha ocupat 25 números: 7 miscel-lànies i 18 monografies (coordinades per 24 editors diferents vinculats a l'UJI). En aquestes 3.494 pàgines s'han publicat 230 articles procedents de la ploma de 257 autors (només 18 han repetit aportacions), que han escrit directament en català (137 articles) o en altres llengües (93 articles) que ha calgut traduir del castellà (62), anglès (13), francès (7), portuguès (4), alemany (3), italià (3) i occità (1). Aquestes 93 
traduccions han estat realitzades pel Servei de Llengües i Terminologia de l'UJI i altres 48 traductors, 21 dels quals han fet més d'una traducció; al mateix temps, 33 de les traduccions (encomanades a estudiants i estudiantes de la titulació de Traducció i Interpretació) han estat revisades per 6 professors del Departament de Traducció i Comunicació. A més, de la vocació divulgadora, pluralista i de rigor científic de l'Anuari, així com de l'orientació universalista, en donen prova les afiliacions de tots els autors participants, procedents de 87 universitats, centres d'ensenyament o de recerca, institucions i empreses: 49 espanyols i 38 de l'estranger (22 d'Europa, 10 d'Amèrica, 4 d'Àsia, 1 d'Oceania i 1 d'Àfrica).

\section{Els convenis amb la Universitat Jaume I}

Amb aquesta exposició queda clar que la trajectòria de l'Anuari és fruit de la col·laboració continuada entre l'Agrupació Borrianenca de Cultura i la Universitat Jaume I, mitjançant tres convenis. El primer el van signar l'any 1992 el síndic major Joan Garí i el rector Francesc Michavila. El segon suposava l'accés universal als continguts de l'Anuari, i el signaven Joan Garí, el rector Vicent Climent i el president del Consorci de Biblioteques Universitàries de Catalunya Antoni González Senmartí. El tercer conveni, més complet i explícit que el primer (amb una vigència de deu anys), se signava el 22 d'octubre de 2012 (vint anys després del primer); en aquest acte van participar el rector (Vicent Climent), el vicerector de Cultura i Extensió Universitària (Wenceslao Rambla), el síndic major de l'ABC (Joan Garí) i el síndic en cap i director de l'Anuari (Joan Verdegal). En la clàusula segona, aquest conveni expressa el següent:

La Universitat hi aportarà la seua gestió tècnica en la correcció i traducció de textos (a través del Servei de Llengües i Terminologia), la gestió i incorporació dels DOI (Digital Object Identifier) per als articles publicats (a través de la Biblioteca) i la inclusió de la revista en el catàleg NEU de les universitats (a través del Servei de Comunicació i Publicacions). L'Agrupació hi aportarà el pagament del cost de la impressió de cadascuna de les revistes, a desgrat de les subvencions públiques o privades que les parts puguen destinar-hi.

\section{Cap al cinquantenari (que serà l'any 2039)}

És evident que una revista com aquesta no podria sobreviure sense el suport directe dels socis i sòcies de l'ABC, que la sufraguen parcialment mitjançant les quotes anuals. Al mateix temps, l'Anuari tampoc hauria estat possible sense el suport econòmic d'un total de 22 entitats oficials o privades, empreses, fundacions o caixes d'estalvi, tant de l'àmbit provincial o valencià com català; els anagrames d'aquestes entitats han ocupat sempre la contracoberta interior de la publicació.

Els socis i sòcies de l'ABC saben que l'Anuari es publica en paper a començaments de cada any i que la versió electrònica, que apareix en Internet el 23 d'abril (Dia del Llibre) de l'any següent, pot consultar-se en línia:

- al RACO: <http://www.raco.cat/index.php/AnuariABC/issue/archive>

- al Repositori de l'UJI: <http://repositori.uji.es/xmlui/handle/10234/4033>

- a la web de l'ABC: <http://www.borriana.com/> 
Els socis han de saber també que les edicions en paper tenen un cost elevat, de manera que els tiratges s'han reduït al llarg dels anys (dels 500 als 250 actuals), però amb suficient cobertura de les necessitats divulgadores de l'Anuari. Mentre les condicions no canvien, els socis i la societat en general podran seguir gaudint de la nostra publicació, del tacte de les pàgines, dels colors i el disseny de les cobertes i - sobretot- de les aportacions escrites d'uns autors i autores que, en un moment determinat, van decidir contribuir desinteressadament a la construcció de la trajectòria d'una revista local amb projecció internacional. Així, encetem ara l'etapa següent, la que ha de portar-nos a l'any 2039, quan alguns afortunats podran celebrar el cinquantenari de l'Anuari.

\section{BIBLIOGRAFIA}

Agrupació Borrianenca de Cultura (1972-2012): Llibres d'actes.

\section{BIONOTA}

\section{Joan Manuel Verdegal i Cerezo}

Natural de Borriana (1955). Llicenciat en Filologia Romànica (Francès) per la Universitat de València (1978). Doctor en Filologia per la Universitat de València (1991). Magíster de Traducció (Francès) per la Universitat de Cantàbria (1993). Ex catedràtic d'Ensenyament Mitjà. Professor titular del departament de Traducció i Comunicació de la Universitat Jaume I. Síndic en cap de l'Agrupació Borrianenca de Cultura i director de l'Anuari des de l'any 1995. Publicacions nacionals i internacionals sobre els premis literaris francesos, la història de la traducció, la recepció de literatura francesa a Espanya, l'explotació de recursos procedents de corpus per a les traduccions, l'ensenyament de la traducció i els premis de traducció. Ha traduït llibres de contingut històric, filosòfic, didàctic i literari.

\section{APÈNDIX: 25 Anuaris (1990-2014)}

Es presenten a continuació totes les cobertes dels Anuaris. Val a dir que, entre els números 8 i 22 , el que es reprodueix són les sobrecobertes o portadelles, amb el disseny exclusiu cedit per Andreu Alfaro (les cobertes pròpiament dites quedaven a l'interior i seguien la pauta dels números 2 a 7 , amb el sumari). En les pàgines següents s'han hagut de sacrificar els colors, però l'evolució cromàtica pot seguir-se fàcilment a les pàgines web indicades més amunt. 


\section{ANUARI}

DE L'AGRUPACIÓ BORRIANENCA DE CULTURA

Revista de recerca humanística i cientifica NUM. I • ANY 1990
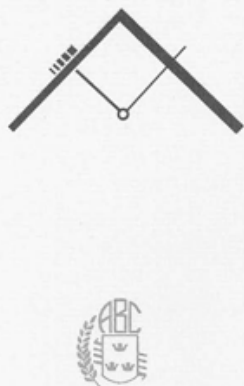

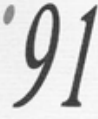

Revista De Recerca Humanistica I Centifica NÚM. 2 SUMARI

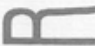

Aušäs Marth i ets tipic Robert Archer

Aprovinacio a ha poesia dEduard Beil Josep 1 Conil

Joan Fuster: lessaig betendor al Pais Valencia Vicent Saliador

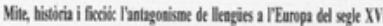
Inga Bierlandt

L'pitafi ànb del mesea de Borriana Cermen Barcelo

Art $\mathrm{i}$ seconatguard Rosalia Torrent

El àner, enigna i repte origens i pescililitsts de preneadi Alfrod Giner Sorolls

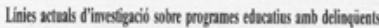
Olga Carbó

Fecililitat $\mathrm{i}$ tipss demprese Naria Ripollks

AGRUPACIÓ BORRIANENCA DE CULTURA

Núm. 1. 1990.

Núm. 2. 1991.
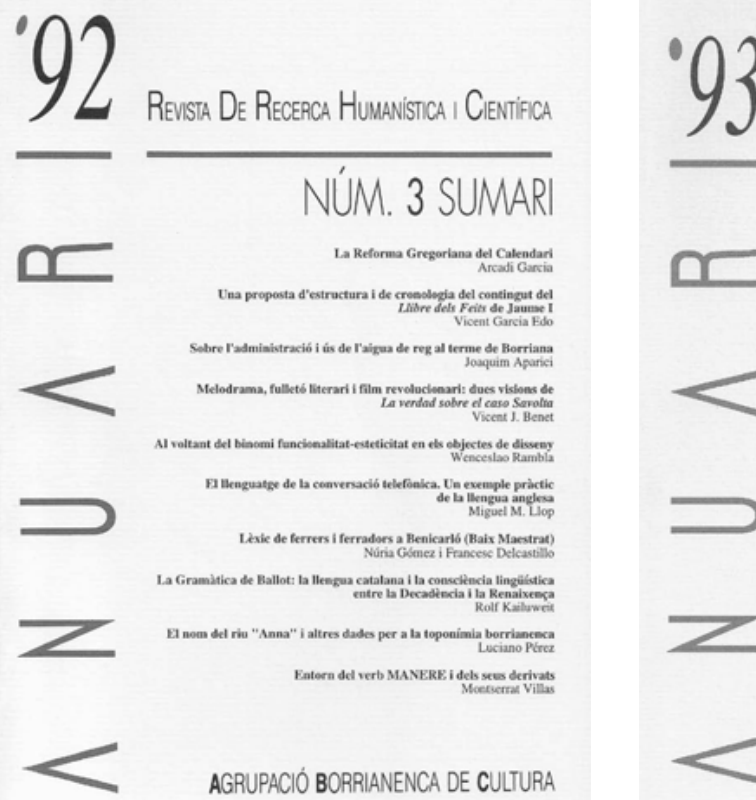

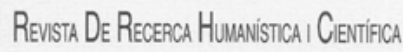
NÚM. 4 SUMAR

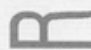

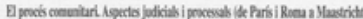
Jan Lais Cina Coliner

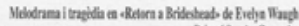
Peterísinatho Condes

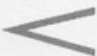

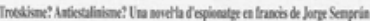

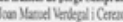

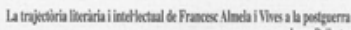
Josep Bilibter

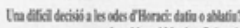

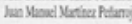

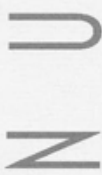

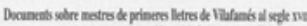

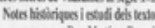
Pers Xartina Bunath

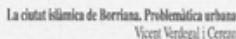

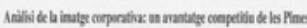
Antros Bles

AGRUPACIÓ BORRIANENCA DE CULTURA

Núm. 3. 1992.

Núm. 4. 1993. 


\section{4}

Renvita De Recegca Hunanistica I Cenvifica
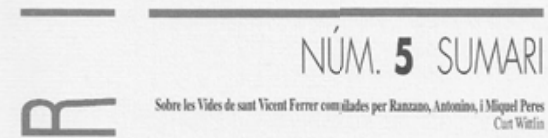

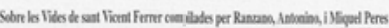
Con Wietin

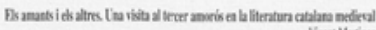
Vicet Matinos

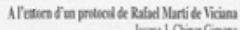
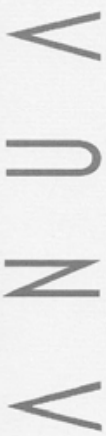

AGRUPACIO BORRIANENCA DE CULTURA

Núm. 5. 1994.

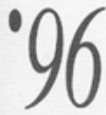

Revsta De Regerca Humanistica I Cenvifica
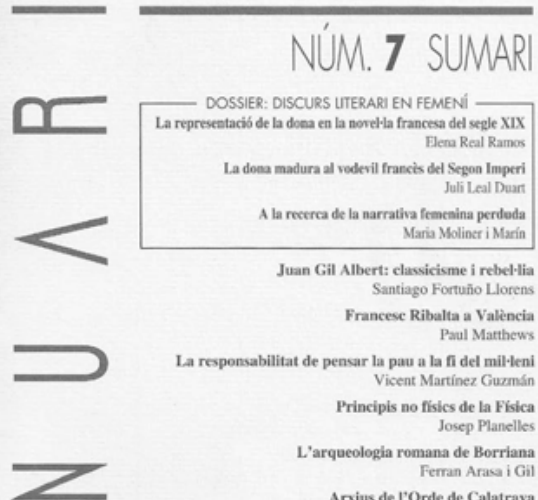

Juan Gil Albert: classicisme i rebel-lia Santiago Fortuño Llorens

Francese Ribalta a València

La responsabilitat de pensar la pau a la fi del milteni Vicent Martinez Guzmín Principis no físics de la Fisica Josep Planelles L'arqueologia romana de Borriana Anius de rOrde de Calatrava Vicent Gil Vicent, Magin Arroyas Serrano Fl barrane d'Aznar (Vilafranca): un lloc a conservar R. Pitarch, J.B. Peris, R. Rosello, E. Sanchis

Agrupació BotrianeEca de CUIURA

Núm. 7. 1996.

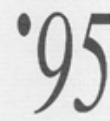

Revista De Regerca Hunwistica I Ceevifica
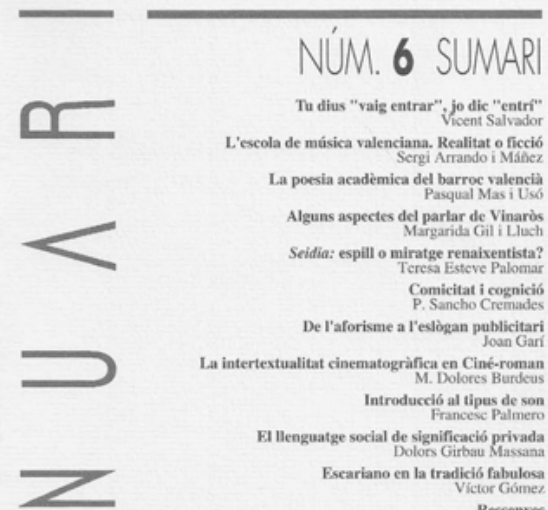

Tu dius "vaig entrar", jo dic "entri" L'escola de música valenciana. Realitat of ficcí La poesia acadèmica del barroc valencià Alguns aspectes del parlar de Vinaròs Seidia: espill o miratge renaixentista? Teresa Esteve Palomar Comicitat i cognició
P. Sancho Cremades De l'aforisme a I'eslògan publicitari
Joan Gari La intertextualitat cinematogràfica en Ciné-roman
M. Dolores Burdeus Introduccí al tipes de son
Francesc Palmero Prancenc Palmero E1 llenguatge social de significació privada Fseariano en la tradicio fabulosa Ressenyes

AGRUPACIÓ BORRIANENCA DE CULTURA

Núm. 6. 1995.

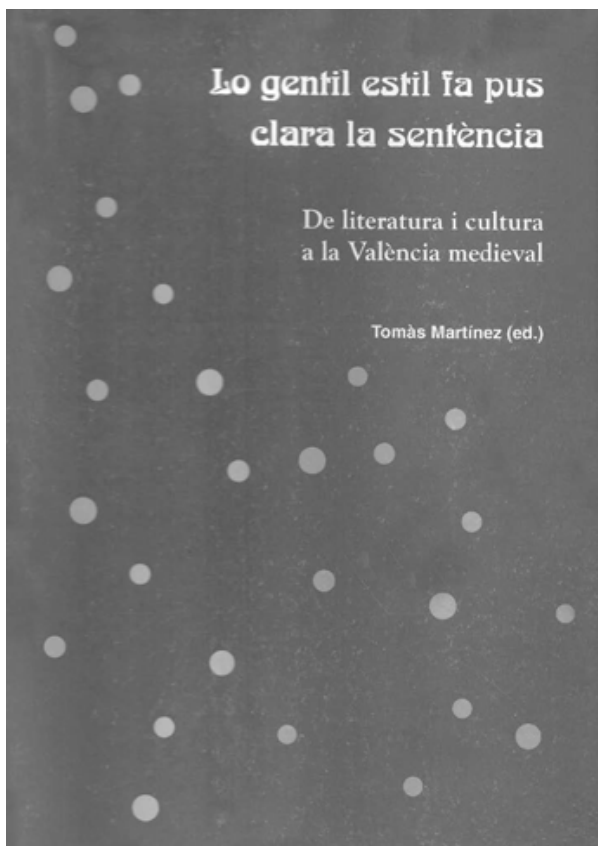

Núm. 8. 1997. 


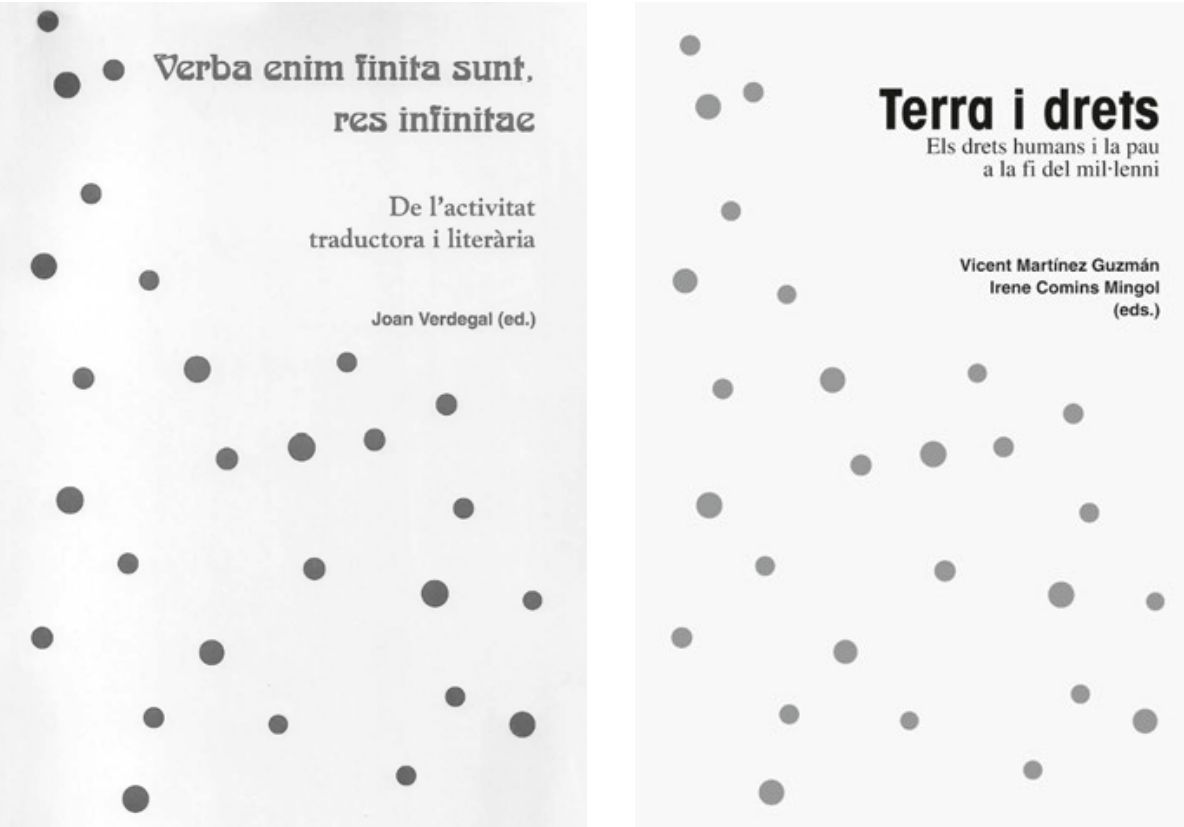

Núm. 9. 1998.

Núm. 10. 1999.

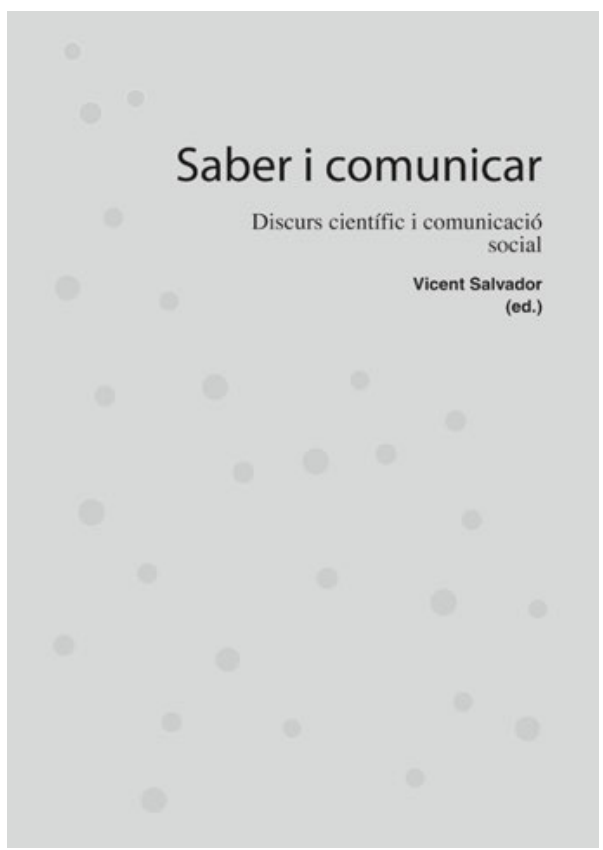

Núm. 11. 2000.

Núm. 12. 2001.

2001:

\section{I'odissea de la física}

Paradigmes $\mathrm{i}$ aplicacions de la física contemporània

Federico Garcia Moliner Josep Planelles Fuster (eds.) 


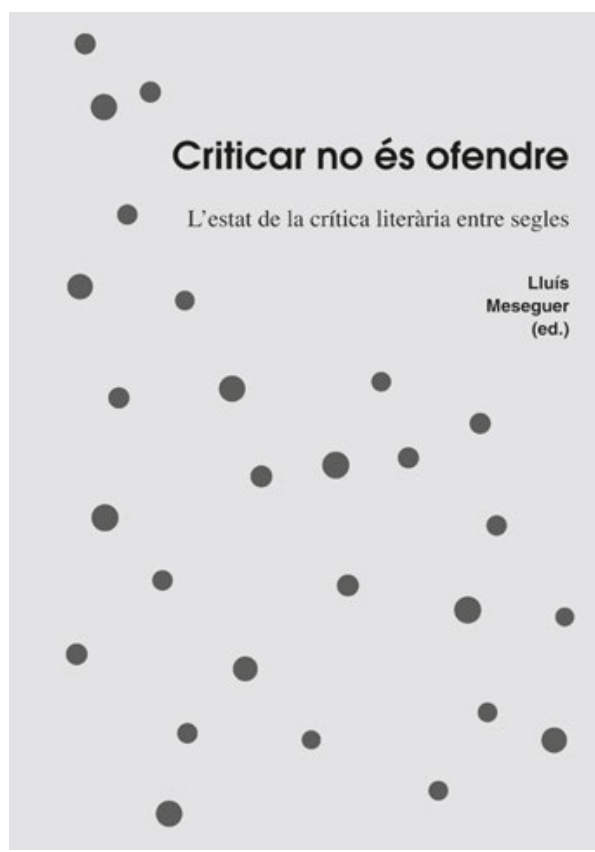

Núm. 13. 2002.

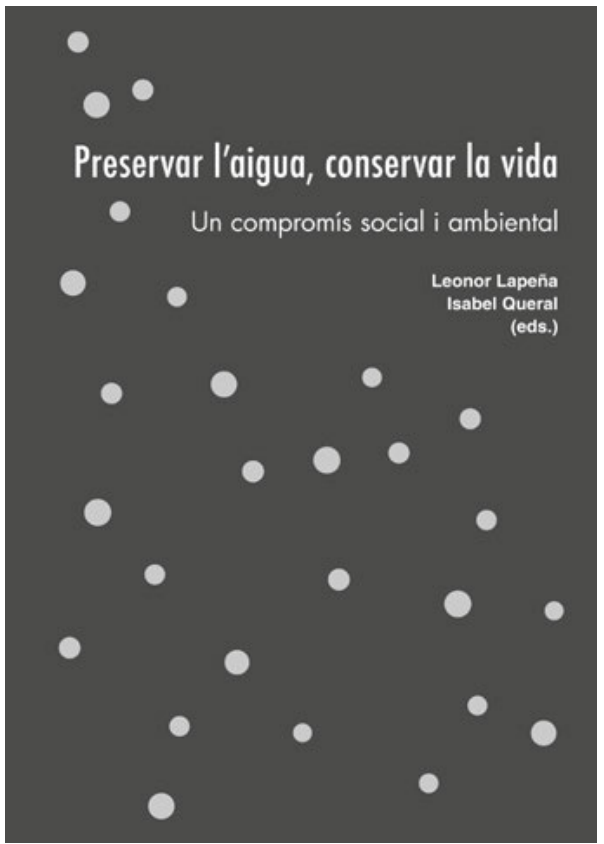

Núm. 15. 2004.

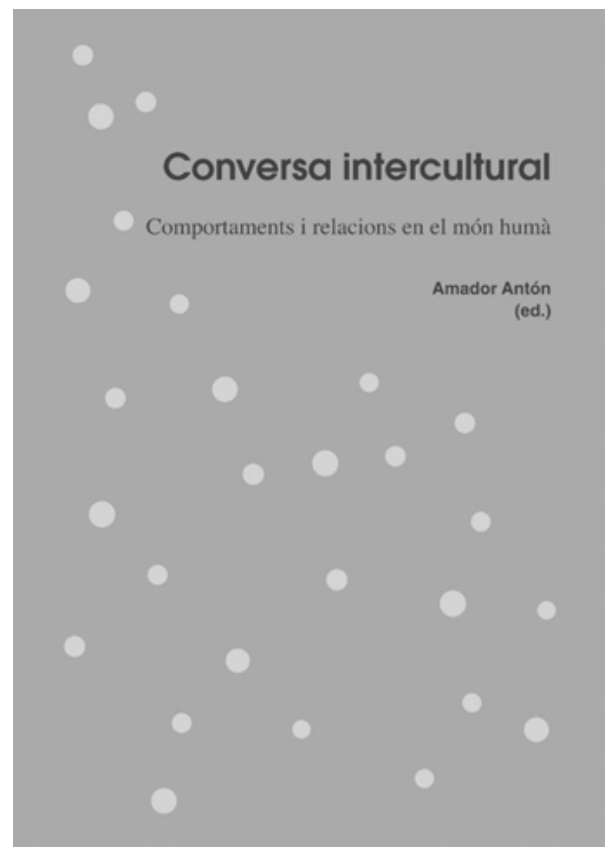

Núm. 14. 2003.

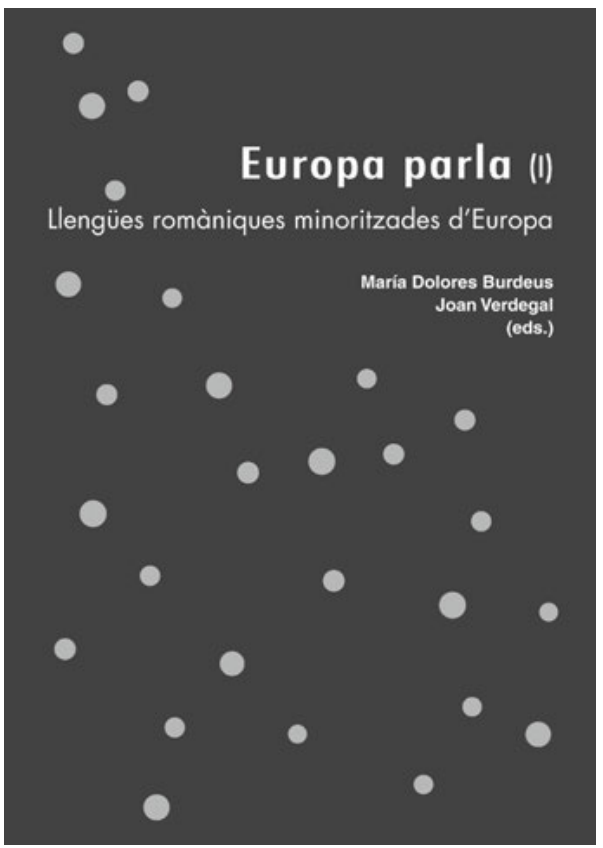

Núm. 16. 2005. 
○

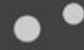

0

\section{Europa parla (II)}

Llengües no romàniques minoritzades d'Europa

○

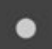

○

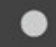

O

○

○

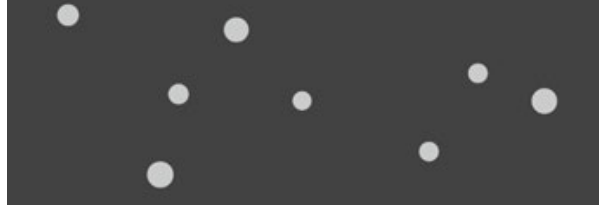

Núm. 17. 2006.

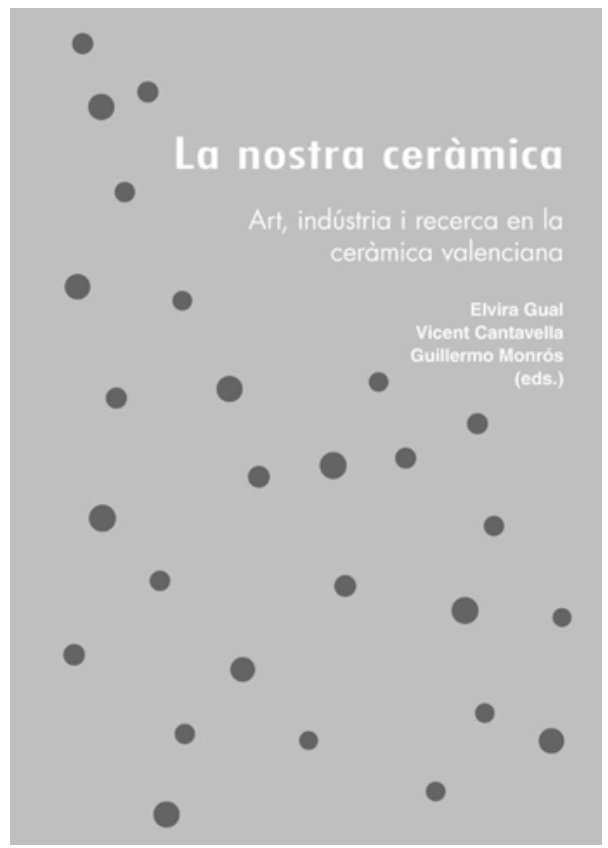

Núm. 19. 2008.
○

0

L'autonomia retrobada O

Perspectives i prospectives del País Valencià

(1707-2007)

○

○

Vicent Ortells Chabrera

Joan Verdegal

(eds.)

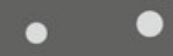

○

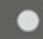

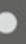

○
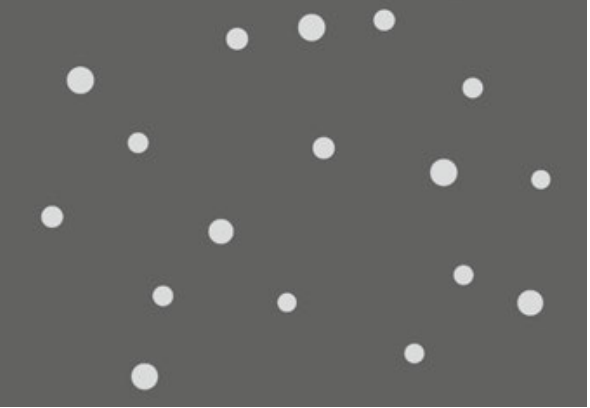

Núm. 18. 2007.

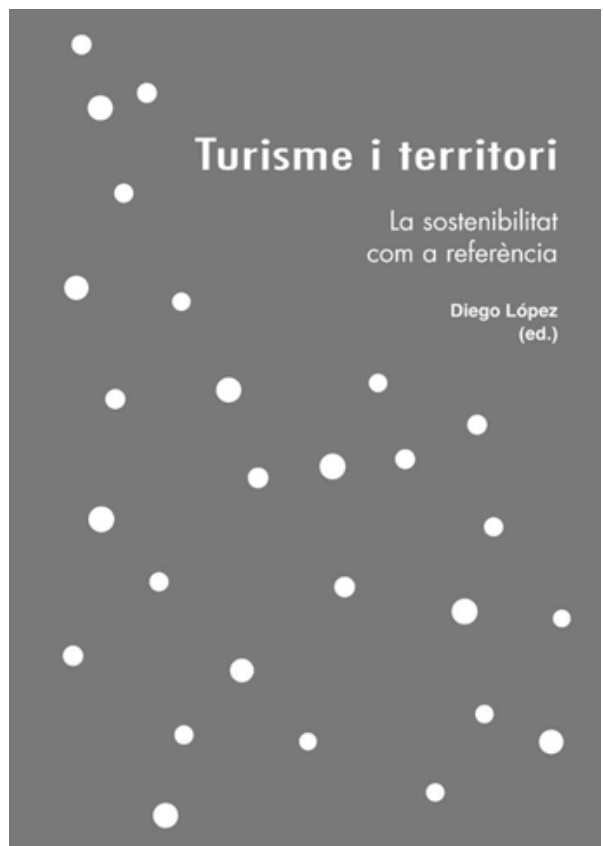

Núm. 20. 2009. 


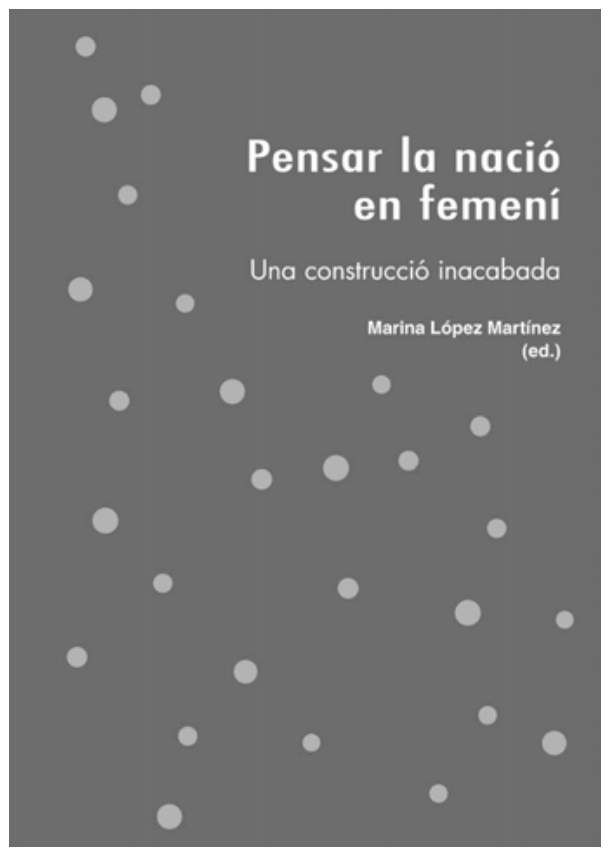

Núm. 21. 2010.

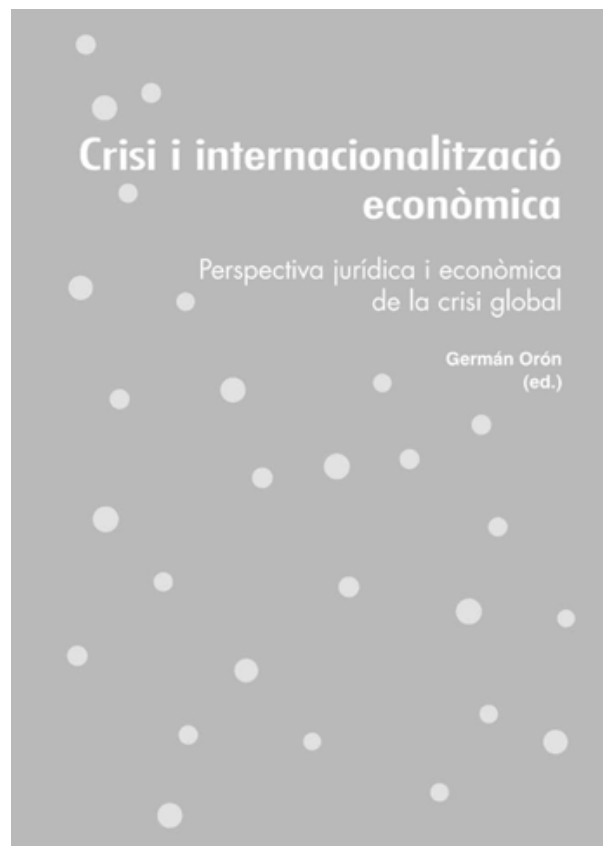

Núm. 23. 2012.

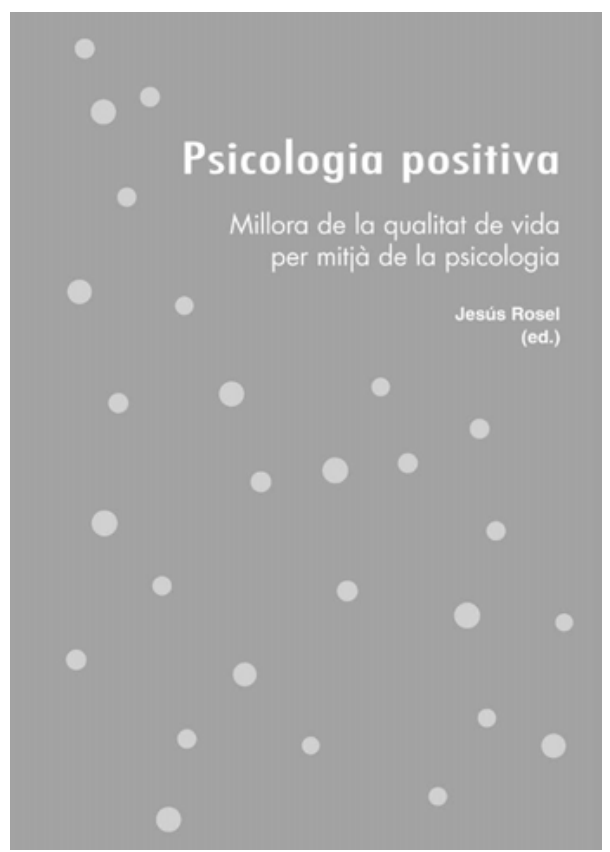

Núm. 22. 2011.

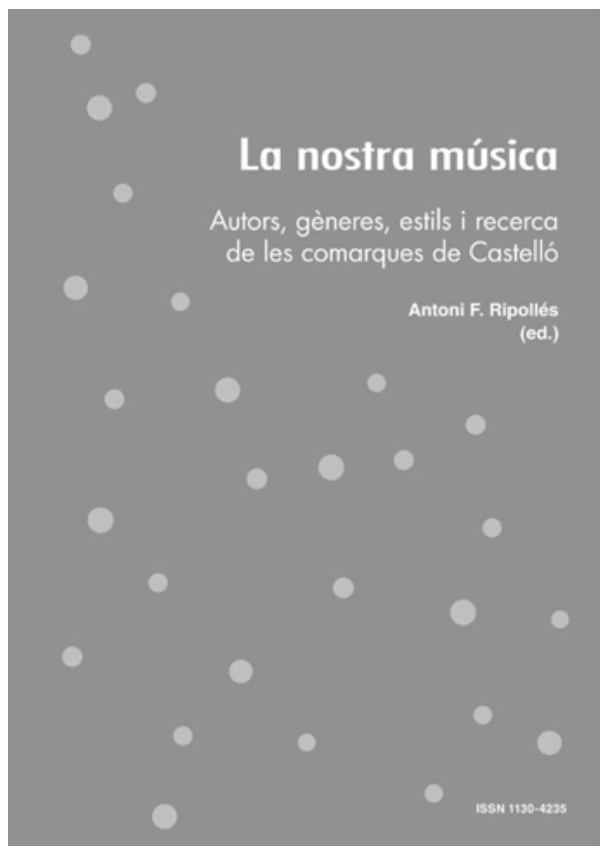

Núm. 24. 2013. 


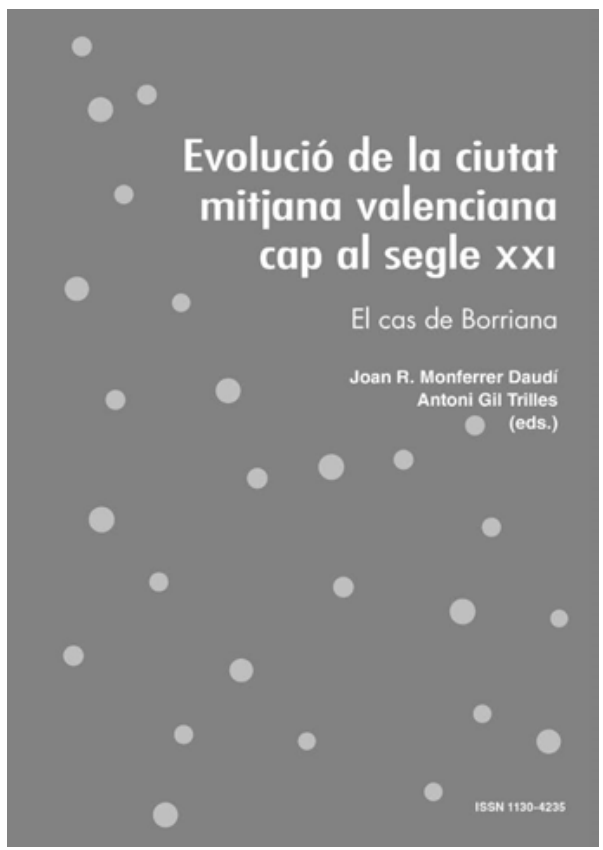

Núm. 25. 2014. 